\title{
Deskripsi dan Preferensi Habitat Udang Air Tawar Macrobrachium rosenbergii (De Man, 1879) dari Sungai Maraja, Toli-Toli, Sulawesi Tengah
}

\section{(Description and Habitat Preference of Freshwater Prawn Macrobrachium rosenbergii (De Man, 1879) from Maraja River, Toli-Toli, Central Sulawesi)}

\author{
Aswandi $^{1 *}$ dan A. Annawaty ${ }^{1}$ \\ ${ }^{1}$ Lab. Biosistematika Hewan dan Evolusi, Jurusan Biologi, Fakultas MIPA Universitas Tadulako Jl. Soekarno Hatta \\ km 9 Tondo, Palu 94118, Sulawesi Tengah, Indonesia.
}

Keywords: Macrobrachium rosenbergii, Sungai Maraja, Sulawesi

Keywords: Macrobrachium rosenbergii, Maraja river, Sulawesi

* Corresponding author aswandibio@gmail.com

\begin{abstract}
Macrobrachium rosenbergii (De Man, 1879) is a freshwater prawn species that have a high economic value because of its relatively large size compared to the other freshwater prawn species. Exploration to find this species in the Maraja River, ToliToli, Central Sulawesi was carried out in January 2019. Sample collected using tray net. Two male specimens of $M$. rosenbergii were found in the river, with maximum size of carapace length reaching $45.94 \mathrm{~mm}$. Macrobrachium rosenbergii has been found in habitats with clay substrate and slow flowing current. This record extended the distribution of $M$. rosenbergii, whose spread in Sulawesi has been known only in the southern part of the island, such as in Makassar, Bone, Pinrang, Wajo and Luwu. In this paper, the morphological characters and line drawing of some character M. rosenbergii from the Maraja River were provided.
\end{abstract}

\begin{abstract}
Abstrak
Macrobrachium rosenbergii (De Man, 1879) adalah salah satu jenis udang air tawar yang memiliki nilai ekonomi tinggi karena ukurannya yang relatif besar dibanding spesies udang air tawar lainnya. Udang ini lebih dikenal sebagai udang galah. Eksplorasi untuk menemukan spesies ini menggunakan alat tray net, di Sungai Maraja, Toli-Toli, Sulawesi Tengah dilakukan pada bulan Januari 2019. Dari hasil eksplorasi tersebut ditemukan dua individu jantan $M$. rosenbergii di bagian hilir Sungai Maraja yang berjarak sekitar $5 \mathrm{~km}$ dari muara sungai. Udang galah ini menempati habitat dengan substrat lumpur dan arus sungai yang lambat. Panjang carapace maksimum dari udang galah yang ditemukan di Sungai Maraja mencapai $45.94 \mathrm{~mm}$. Penemuan ini memperluas wilayah distribusi dari $M$. rosenbergii yang penyebarannya di Sulawesi selama ini diketahui hanya di bagian selatan pulau, yaitu di Makassar, Bone, Pinrang, Wajo dan Luwu. Dalam tulisan ini juga disajikan karakter morfologi dan line drawing beberapa bagian dari $M$. rosenbergii yang ditemukan di Sungai Maraja.
\end{abstract}

\section{Latar Belakang}

Udang galah yang memiliki nama ilmiah Macrobrachium rosenbergii (De Man, 1879) adalah salah satu jenis udang air tawar yang memiliki nilai ekonomi tinggi (Benzie, 1982), karena ukurannya yang relatif besar dibanding spesies udang air tawar lainnya. Menurut Holthuis (1980), udang galah dapat mencapai ukuran hingga $320 \mathrm{~mm}$ pada individu jantan dan 250 $\mathrm{mm}$ pada yang betina.

Macrobrachium rosenbergii pertama kali dideskripsi oleh De Man pada tahun 1879 berdasarkan koleksi udang air tawar dari Timika, Irian Jaya, Indonesia. Wowor and $\mathrm{Ng}$ (2007) melaporkan spesies ini terdistribusi dari Filipina termasuk Palawan Island, 
Lesser Sunda Island, Papua New Guinea dan Australia bagian utara. Penyebaran spesies ini cukup luas di Pulau Sulawesi berdasarkan laporan yang berasal dari berbagai wilayah di Sulawesi. Schenkel (1902) melaporkan spesies ini terdapat di Kema, Sulawesi, Indonesia. Wowor and $\mathrm{Ng}$ (2007) melaporkan $M$. rosenbergii yang dikoleksi dari Sungai Cenrana, Bone. Wahidah et al., (2015) melaporkan spesies ini dikoleksi dari Sungai Kariango, Pinrang, Sungai Wellawi, Luwu dan Danau Tempe, Wajo.

Macrobrachium rosenbergii yang terdistribusi di Malaysia ditemukan pada kondisi habitat dengan arus air yang tenang (Johnson, 1967), sama halnya dengan yang ditemukan di Sulawesi Selatan (Wahidah et al., 2015).

Sungai Maraja merupakan salah satu sungai yang ada di Sulawesi Tengah dengan kondisi sungai di bagian hilir yang berarus lambat dengan substrat berlumpur (observasi pribadi). Berdasarkan informasi dari penduduk di sekitar sungai, di bagian hilir Sungai Maraja sering ditemukan udang air tawar yang berukuran besar, yang diberi nama "Lando" oleh penduduk sekitar. Namun demikian, tidak ada informasi ilmiah yang tersedia mengenai apakah "Lando" tersebut adalah spesies $M$. rosenbergii ataukah spesies udang air tawar lainnya? Karena itu, tujuan penelitian ini adalah untuk mengidentifikasi udang air tawar "Lando" yang ada di bagian hilir Sungai
Maraja dan mengetahui preferensi habitat dari udang tersebut.

\section{Bahan dan Metode}

Pengambilan sampel udang air tawar dilakukan pada bulan Januari 2019 di bagian hilir Sungai Maraja, ToliToli, Sulawesi Tengah yang berjarak $\pm 5 \mathrm{~km}$ dari muara sungai dengan koordinat yaitu $00^{\circ} 50 ' 54.7 " \mathrm{~N}$, 120-37'58.2"E dan ketinggian $4 \mathrm{~m}$ dpl (Gambar 1). Sampel dikoleksi menggunakan tray net kemudian dipreservasi ke dalam botol yang telah berisi alkohol $96 \%$.

Identifikasi sampel dilakukan di Laboratorium Biosistematika Hewan dan Evolusi, Jurusan Biologi, FMIPA, Universitas Tadulako, menggunakan acuan kunci identifikasi Wowor et al., (2004). Spesimen Macrobrachium rosenbergii yang telah diidentifikasi selanjutnya disimpan sebagai spesimen koleksi di Laboratorium Biosistematika Hewan dan Evolusi, Jurusan Biologi, FMIPA, Universitas Tadulako, Palu.

\section{Hasil dan Pembahasan}

Berdasarkan identifikasi yang telah dilakukan, dapat dikonfirmasi bahwa udang air tawar berukuran besar yang ditemukan di bagian hilir Sungai Maraja, yang disebut "Lando" adalah spesies Macrobrachium rosenbergii.

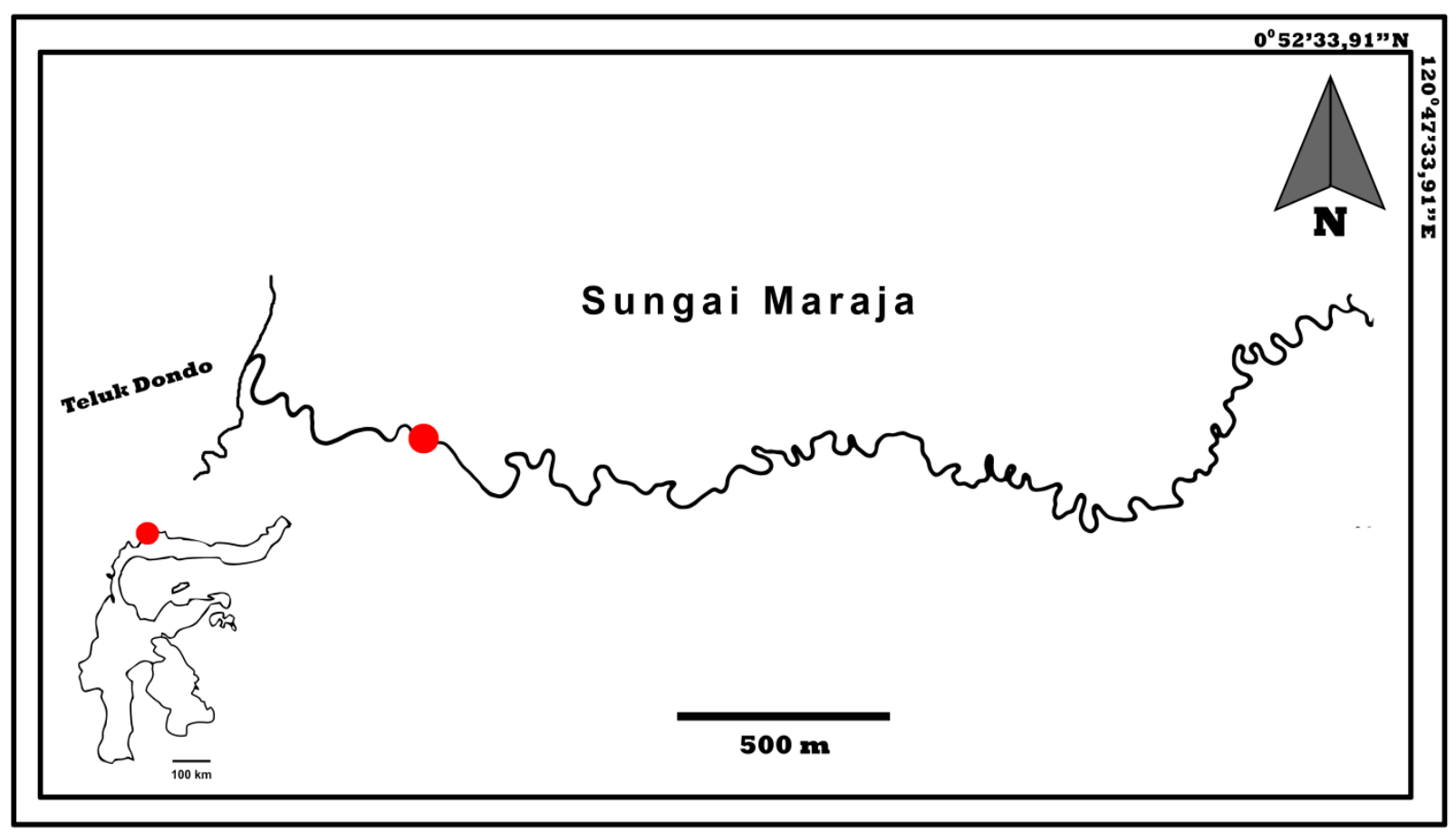

Gambar 1. Lokasi ditemukannya Macrobrachium rosenbergii di Sungai Maraja (ditandai lingkaran merah) 


\section{Macrobrachium rosenbergii (De Man, 1879) Catatan spesimen}

Dua jantan (CL max: $45.94 \mathrm{~mm}$ ), Sungai Maraja, kolektor Aswandi, Januari 2019.

\section{Diagnosis}

Rostrum panjang dan mencapai ujung scaphocerite, rumus gigi rostral (3) $+9 / 11$, ukuran panjang karapas menggunakan istilah carapace length (CL max: 45.94 $\mathrm{mm}$ ), post antennular carapace margin lurus (Gambar 2A, 2B). Panjang kaki jalan pertama melebihi ujung scaphocerite serta terdapat rambut halus dan jarang pada ujung capit. Kaki jalan kedua langsing dan memiliki panjang yang sama antara kiri dan kanan, terdapat duri yang jarang pada permukaan, dactylus pada chela ditutupi oleh pubescence yang tebal. Panjang carpus 1.3 kali dari merus pada kaki jalan kedua (Gambar 2C). Mobile mesial spine pada uropod lebih pendek dari distolateral.
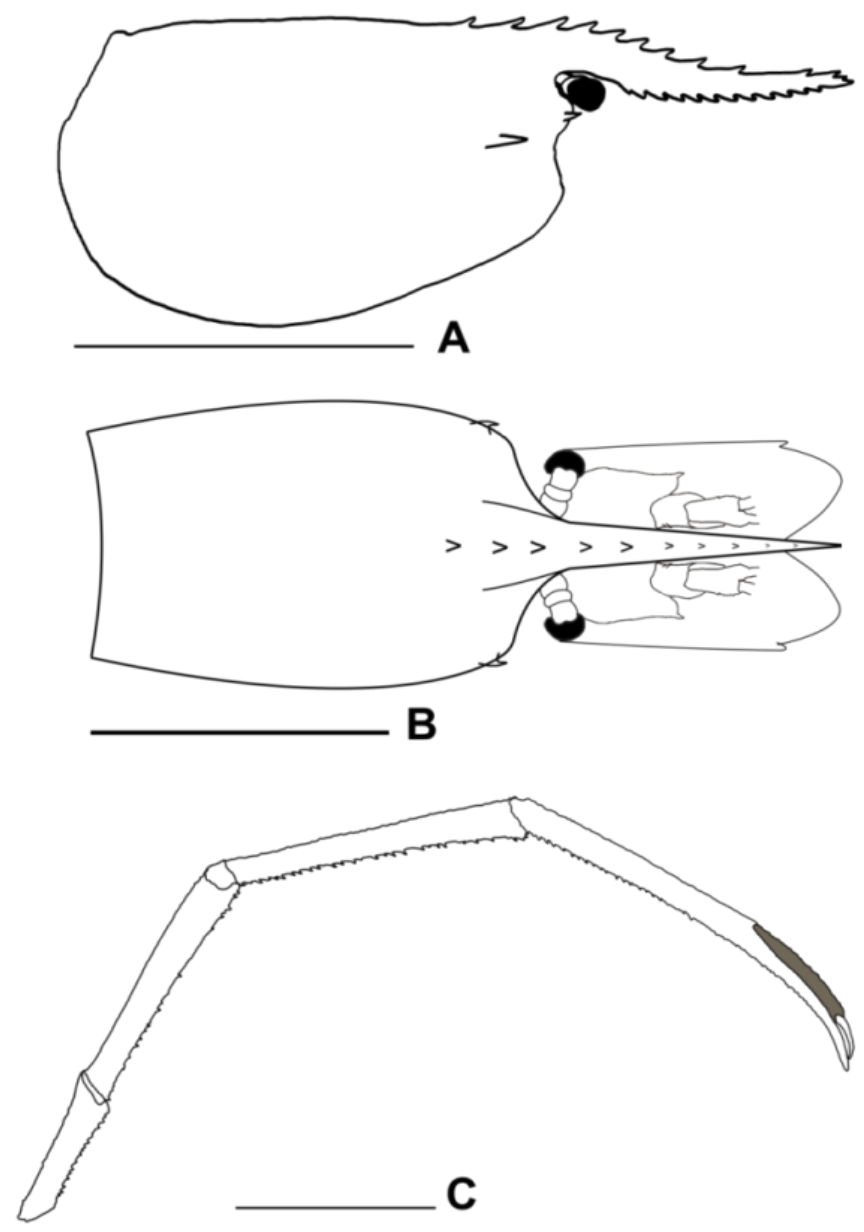

Gambar 2. Macrobrachium rosenbergii (De Man, 1879), jantan (CL $45.94 \mathrm{Cm}$ ), Sungai Maraja. (A) Tampak samping cephalothorax, (B) Tampak atas cephalothorax, (C) Kaki jalan kedua. Skala A, B, C: 7 Cm.

\section{Preferensi Habitat}

Macrobrachium rosenbergii tersebar luas di sungai (Johnson, 1967). Spesies ini ditemukan di bagian hilir Sungai Maraja yang berkisar $5 \mathrm{~km}$ dari muara sungai pada habitat di antara akar tumbuhan air dengan substrat lumpur, kedalaman sungai berkisar $\pm 2 \mathrm{~m}$, arus sungai yang lambat dan badan sungai ditutupi vegetasi pohon. Menurut Johnson (1967), M. rosenbergii dewasa mampu bertahan hidup di arus air yang tenang dan pada fase larva membutuhkan air laut dalam tahap perkembangbiakannya. Jenis ini umumnya ditemukan di air payau, bahkan kadangkadang terdapat di air laut (Hothuis, 1950), karena itu dalam studi ini, $M$. rosenbergii tidak ditemukan pada bagian sungai yang ke arah hulu karena bagian hulu sungai memiliki salinitas yang sangat rendah.

Macrobrachium rosenbergii yang ditemukan di Sungai Maraja berada pada habitat dengan $\mathrm{pH} 7$ dan suhu $28.2 \stackrel{\circ}{\circ} \mathrm{C}$. Spesies tersebut ditemukan pada $\mathrm{pH} 7.5$ dan berkembangbiak dengan baik pada kisaran suhu air 28-30 ํ (Johnson, 1967; Tayamen, 2001).

\section{Distribusi}

Macrobrachium rosenbergii pertama kali ditemukan di Timika, Irian Jaya, Papua (Chace and Bruce, 1993). Jenis $M$. rosenbergii tersebar luas di Papua New Guinea, Filipina sampai ke Lesser Sunda Island dan Australia (Wowor et al., 2009). Jenis ini juga terdistribusi luas di India sampai ke China bagian selatan, Malaysia, Thailand, Sri Lanka, Bangladesh, Myanmar dan Vietnam (Chace and Bruce, 1993; Tayamen, 2001).

Di Indonesia, spesies ini memiliki nilai ekonomi tinggi dan tersebar di beberapa pulau yaitu Sumatra, Jawa, Borneo, Sulawesi dan Lesser Sunda Islands (Djajadiredja and Sachlan, 1956 dalam Holthuis, 1980). Wowor and $\mathrm{Ng}$ (2007) melaporkan koleksi spesimen $M$. rosenbergii dari Papua, Halmahera dan Makassar. Penyebaran spesies ini di Sulawesi baru tercatat di bagian selatan pulau, telah dilaporkan terdapat di Bone, Pinrang, Luwu dan Wajo (Wowor and Ng, 2007; Wahidah et al., 2015).

Macrobrachium rosenbergii yang ditemukan di Sungai Maraja memiliki panjang maksimum carapace 45.94 $\mathrm{mm}$, lebih besar dari spesimen yang diperoleh dari daerah di Sulawesi Selatan. Spesimen yang berasal dari Luwu memiliki ukuran maksimum carapace 18.34 $\mathrm{mm}$, dari Pinrang memiliki ukuran maksimum carapace $13.08 \mathrm{~mm}$ dan spesimen dari Wajo dengan ukuran maksimum carapace $10.17 \mathrm{~mm}$ (Wahidah et al., 2015). 
Macrobrachium rosenbergii menjadi salah satu komoditas utama di beberapa daerah di Indonesia sehingga jenis ini memiliki nama lokal tersendiri bagi tiap-tiap daerah. Macrobrachium rosenbergii dikenal sebagai "Udang satang" di Jawa, sedangkan di Kalimantan disebut "Udang galah" (Holthuis, 1950). Udang galah yang ditemukan di Sungai Maraja, ToliToli diberi nama "Lando" oleh penduduk lokal, juga sebagai salah satu komoditas yang bernilai ekonomi tinggi, sehingga berpotensi untuk dijadikan sebagai udang budidaya di wilayah ini kemudian hari.

Penemuan spesies $M$. rosenbergii di Sungai Maraja, Toli-Toli, Sulawesi Tengah ini menambah catatan baru mengenai distribusi spesies ini di Sulawesi.

\section{Ucapan Terima Kasih}

Terima kasih kepada Dr. Ir. Daisy Wowor, M.Sc., dan Bapak Ujang Nurhaman atas bimbingannya dalam proses identifikasi sampel. Kepada Moh. Basit, Puji Rahayu, Rizki Ramadhana Takdim dan $\mathrm{Ni}$ Luh Setiawati yang telah membantu dalam proses pengambilan sampel di lapangan. Sebagian penelitian ini didanai oleh Anggaran Penelitian Hibah Penelitian Dasar pada tahun 2019 berdasarkan Surat Keputusan Nomor 351.u/UN28.2/PL/2019 dan Perjanjian Kontrak Nomor 100/SP2H/LT/DRPM/2019 yang diberikan kepada penulis kedua.

\section{Daftar Pustaka}

Benzie, J. A. H., 1982, The complete larva development of Caridina mccullochi Roux, 1926 (Decapoda, Atyidae) read in the laboratory. Crustacean Biology, 2: 493-513.

Chace, F. A., and Bruce, A. J., 1993, The caridean shrimps (Crustacea: Decapoda) of the Albatross-Philippine Expedition, 1907-1910. Part 6. Superfamily Palaemonoidea. Washington: Smithsonian Institution Press.

De Man, J. G., 1879, On some species of the genus Palaemon Fabr. With descriptions of two new forms. Notes from the Royal Zoological Museum of the Netherlands at Leyden, 1(41):165-184.

Djajadiredja, R., and Sachlan, M., 1956, Shrimp and prawn fisheries in Indonesia with special reference to the Kroya District. Proc. IPFC, 6: 366-377.
Holthuis, L. B., 1950, The Decapoda of the SibogaExpedition. Part X. The Palaemonidae collected by the Siboga and Snellius expedition with remaks on other species. Subfamily Palaemonidae, Siboga-Exped. Monogr, 39(9): $1-268$.

Holthuis, L. B., 1980, Shrimps and prawn of the world. An annotated catalogue of species of interest to fisheries (pp. 271). Rome: Food and Agriculture Organization of the United Nation Publishing.

Johnson, D. S., 1967, Some factors influencing the distribution of freshwater prawns in Malaya. Proc. Sym. Crust. Ernakulam, India, 1965(1): 418-433.

Schenkel, E., 1902, Contribution to the knowledge of the Decapod fauna of Celebes, Negotiations of the Naturforschenden Gesellschaft in Basel (13): 485-585.

Tayamen, M. M., 2001, Biology and Hatchery Management of the giant freshwater prawan Macrobrachium rosenbergii - de Man. Departmen of Agriculture, Bureau of Fisheries and Aquatic Resources, 10: 1-6.

Wahidah, Omar, S. B. A., Trijuno, D. D., and Nugroho, E., 2015, Morphometric Variance of South Sulawesi's Freshwater Prawn Macrobrachium rosenbergii and Macrobrachum idae. Internationa Journal of Scientific and Research Publication, 5(4): 2250-3153.

Wowor, D., Cai, Y., and Ng, P. K. L., 2004, Crustacea: Decapoda, Caridea. In: C. M. Yule \&amp; H. S. Yong (eds.) (337-375), Freshwater invertebrates of the Malaysian Region. Kuala Lumpur: Academy of Sciences Malaysia press.

Wowor, D., and Ng, P. K. L., 2007, The giant freshwater prawns of the Macrobrachium rosenbergii species group (Crustacea: Decapoda: Caridea: Palaemonidae). The Raffles Bulletin of Zoology, 55(2): 321-336.

Wowor, D., Muhtu, V., Meier, R., Balke, M., Cai, Y., and $\mathrm{Ng}, \mathrm{P} . \mathrm{K}$. L., 2009, Evolution of life history traits in Asian freshwater prawns of the genus Macrobrachium (Crustacea: Decapoda: Palaemonidae) based on multilocus molecular phylogenetic analysis. Mol Phylogenetics Evol, 52(2): 340-350. 